\title{
Heavy Metals Characterization of Sludge from a Philippine Recycling Paper Mill
}

\author{
Lorraine A. Carrillo \\ Susan M. Gallardo \\ Asian Regional Research Program on Environmental Technology \\ De La Salle University-Manila \\ 2401 Taft Avenue, 1004 Manila, PHILPPINES \\ Email: gallardos@dlsu.edu.ph
}

\begin{abstract}
Wastewater treatment sludge, which is the largest volume residual waste stream generated by the pulp and paper industry, is generally disposed of in a dedicated landfill. Composting the sludge is an alternative method proposed by the Asian Regional Research Program on Environmental Technology-De La Salle University (ARRPET-DLSU) Minor Issue Group. The Philippine Department of Agriculture's (DA) standards for an organic fertilizer's maximum allowable content of heavy metals provided the legislative regulation for the conversion of sludge to compost. The research was designed to characterize the sludge samples from TIPCO, a Philippine paper-recycling mill, and establish whether the sludge contained the heavy metals cadmium, chromium, lead, mercury, nickel, and zinc using atomic absorption spectrophotometer (AAS). Sampling was done for four weeks during newsprint and white paper production. Three discharge terminals were established as sampling points. The samples showed that the metal content of the sludge vary from point to point and was highest throughout the manufacture of white paper. Chromium, mercury, and nickel, however, were nondetectable in all the samples, while cadmium was detectable only in very few samples. Lead and zinc were present at all three points and were highest at the deinking sludge. Comparing the results with Part 503 of the United States EPA and the DA's guidelines for organic fertilizers yield significantly lower parameter values. Composting the sludge was, therefore, found to be a feasible option for recycling paper-mill sludge since the metal content were very low compared to local and international standards.
\end{abstract}

Keywords: Composting, deinking, heavy metals, pulp-and-paper recycling mill, sludge, and wastewater treatment.

\section{INTRODUCTION}

One of the most pressing problems today worldwide is safe disposal of large quantities of industrial wastes including pulp and paper mill wastes.

The reuse of waste paper in papermaking inevitably results in the generation of process residues that cannot be used in paper production
(Webb 1996). Sludge is an inevitable by-product of recycling (Wiseman et al. 2000).

The amount of sludge generated by a recycled paper mill is greatly dependent on the furmish being used and the end product being manufactured. Paper sludge obtained directly from a mill wastewater treatment plant is composed generally of $50-75 \%$ organics (cellulose fibers and tissues) and $30-50 \%$ kaolinite clay (Medvitz 1998). The 
Philippine pulp-and-paper subsector manufactures paper and paperboards from wood and nonwood pulp, as well as from recycled fibers or waste paper. Waste paper is the major source of raw material accounting for as much as $90 \%$ of printing and writing paper production (UP Business Research 1990).

Potential environmental hazards from wastewater sludge are associated with trace metal constituents that partition from the effluent into the sludge (MacGuire 1997). The major source of paper sludge contamination comes from the dyes added to the paper by manufacturers and to the inks added by printers, as well as from the organochlorine contaminants added during the bleaching process by paper producers (http:// www. conservatree.Com/learn/essential_Issues/ EIPaperContents $/ \mathrm{shtml}$ ).

The Philippines has 1 integrated pulp-andpaper mill, 4 abaca pulp mills, and 37 recycling mills (Rios 2001). A survey of the pulp-andpaper industry discharges of the Philippines by the Asian Regional Research Program on Environmental Technology-De La Salle University (ARRPET-DLSU) had eleven 11 respondents out of the 42 mills in the country (Gallo and Gallardo 2002). Of these respondents, 10 mills are still operational with all recycling paper mills running 24 -hours each day. These mills generate sludge that range from 1.5 to $100 \mathrm{MT}$ each day and utilize both local and imported raw materials as furnish. Solid wastes, including generated mill garbage, are either landfilled, recycled, and/or burned (Bantayan and Razal 2001).

All developed countries have been very successful in increasing the proportion of waste paper that is recovered and converted into new paper. A majority of nonintegrated paper mills in the Philippines rely on imports for their supply of raw materials because the country has the lowest recovery rate for waste paper among Asian nations.

Sludge management in developed countries includes composting. Pulp-and-paper mill sludge are amenable to well-controlled composting techniques. However, soil contamination may result from heavy metals, pathogens, or persistent toxic organics, which can occur in composted materials (Barry et al. 2000). Trace metal contamination of soil and water can lead to health problems for the exposed population.

In the Philippines, compost products intended for distribution commercially must conform to the standards for organic fertilizers set by the Philippine Department of Agriculture (DA). Table 1 presents the maximum allowable level of heavy metals in organic ferilizers or compost prescribed by the Department of Agriculture (DA).

The present research was conducted to assess the heavy-metal content of sludge provided by ARRPET-DLSU's chosen partner, Trust International Paper Corporation (TIPCO), a Philippine recycling paper mill.

The problem of sludge discharges from a recycled pulp-and-paper mill is among the minor issues being ardressed by ARRPET. Among the potential advantages of characterizing sludge is to provide evidence for the safe conversion of sludge to compost. If proven benign, the sludge can be composted or landspread without processing. The results of the study, however, would be relevant only to the specific mill cited as the supplier of the sample sludge.

\section{THEORY}

Sludge handling usually begins with blending, during which sludge from a variety of sources are mixed to facilitate in subsequent processing.

Sulfuric acid is added to the influent wastewater at the plant to maintain a $\mathrm{pH}$ range of 6-8 in preparation for the biological treatment in the aeration basin. The wastewater in the influent pit is pumped into the primary clarifier. The clarified waterspill flows over by gravity to the two activated sludge basins while settled sludge is removed by a center-mounted sludge scraper and is discharged to the sludge holding tank, which serves as a storage tank for the primary sludge. The settled sludge is then pumped into the sludge-mixing tank and the polymers are added for effluent thickening and dewatering.

At the aeration basins, the clarified water is subjected to biological treatment via the activated sludge process, removing dissolved organics such as biochemical oxygen demand (BOD) and chemical oxygen demand (COD). Sodium 
hypochlorite is added to control the excessive growth of bacteria.

The product of the biological treatment in the aeration basins is a mixture of sludge and water. This mixture is then pumped into the secondary clarifier and treated. The treated water overflow is discharged into the final pond and ultimately into a creek.

The settled sludge collected at the bottom of the secondary clarifier is pumped back into the aeration basins as returned activated sludge to maintain the desired mixed-liquor suspended solids concentration. The excess sludge is wasted after dilution with water. At the suction of the pump leading to the dissolved air flotation (DAF), the excess sludge is injected with polymer for the coagulation and flocculation of suspended matter. The flocs are separated from the water via adhesion, absorption, or entrapment through air injection. The air floats the flocs on the surface forming froths which are then removed by mechanical skimmers. Then, the filtrates are discharged into the final pond.

The Voiths machines and the Andritz machines dewater the sludge from the air flotation. The dewatered sludge is disposed into the landfill while the filtrate goes back to the influent pit.

The deinking plant processes turn in pulp of the desired quality and ensures further the absence of contaminants in preparation for papermaking. Nonfibrous materials are removed through a combination of cleaning, screening, flotation deinking, and washing.

Table 1. Allowable Level of Heavy Metals in Organic Fertilizers (Obcemea 2001)

\begin{tabular}{|c|c|}
\hline Metals & $\begin{array}{c}\text { Maximum Allowable } \\
\text { Level in Compost (ppm) }\end{array}$ \\
\hline $\mathrm{Zn}$ & 1,000 \\
\hline $\mathrm{Pb}$ & 750 \\
\hline $\mathrm{Cu}$ & 300 \\
\hline $\mathrm{Cr}$ & 150 \\
\hline $\mathrm{Ni}$ & 50 \\
\hline $\mathrm{Hg}$ & 5 \\
\hline $\mathrm{Cd}$ & 5 \\
\hline
\end{tabular}

Cleaners and screens eliminate various contaminants such as paper clips, staple wires, and adhesives. At the flotation cell, ink is separated from the fiber. With the introduction of air and soap, bubbles form and rise to the surface along with the ink that adheres to them. These are subsequently rejected from the process by controlling the flotation cell level. Bleaching is done by using chemicals to attain the required brightness of the pulp.

\section{EXPERIMENT}

Samples were taken from the blended sludge, primary clarifier, and deinking tank. A total of 51 samples were collected from the wastewater treatment plant. Sample collection which spanned four weeks involved three weeks of newsprint run and a week of white run operation. Six samples of blended sludge (mixed primary and secondary sludge) were collected for each week. The samples, each weighing less than $200 \mathrm{~g}$, were collected using plastic scoop samplers for sludge and placed in 150-ml widemouthed polyethylene bottles with Teflon ${ }^{\circledR}$-lined caps. The samples were then brought to De La Salle University-Manila for analysis. The hold time for each analyte is six months.

Collection was done twice a day at the three discharge points. The samples were taken between 9:00 and 2:00. Sampling, however, was postponed when power fluctuations at the site resulted in an overflow at the discharge or sampling point.

A well-mixed sample of $1-2 \mathrm{~g}$ was acid digested using the U.S. EPA Method 3050 (Acid Digestion of Sediment, Sludge, and Soils) except for mercury in which the cold vapor technique, or U.S. EPA Method 7471A, was employed. The specimen was treated with $10 \mathrm{ml}$ of $1: 1 \mathrm{HNO}_{3}$ and then heated. Two additional increments of $\mathrm{HNO}_{3}$ were added and heating was continued to decompose the organic matrix. Further decomposition of the organic matrix was accomplished by continued heating and the addition of up to five $2-\mathrm{ml}$ increments of $30 \%$ $\mathrm{H}_{2} \mathrm{O}_{2}$. Concentrated $\mathrm{HCl}$ was added to the digested sample which was then placed on/in the heating source. After cooling, insoluble materials were removed by filtration. The filtrate was diluted 
to $100 \mathrm{ml}$ in a volumetric flask. Quality control samples were prepared for every batch of 10 samples or whenever a new sample matrix was being analyzed. Table 2 identifies the analytical method for the heavy metals.

Table 2. Analytical Methods (SWS-846 1994)

\begin{tabular}{|c|c|c|}
\hline Parameter & $\begin{array}{c}\text { Method } \\
\text { Description }\end{array}$ & $\begin{array}{c}\text { Analytical } \\
\text { Method }\end{array}$ \\
\hline $\mathrm{Cd}$ & $\begin{array}{c}\text { Flame Atomic } \\
\text { Absorption } \\
\text { Spectrophotometry } \\
\text { (FLAA) }\end{array}$ & $\begin{array}{c}7130 \\
3050 \text {-Digestion }\end{array}$ \\
\hline $\mathrm{Cr}$ & FLAA & $\begin{array}{c}7190 \\
3050-\text { Digestion }\end{array}$ \\
\hline $\mathrm{Pb}$ & FLAA & $\begin{array}{c}7420 \\
3050-\text { Digestion }\end{array}$ \\
\hline $\mathrm{Ni}$ & FLAA & $\begin{array}{c}7520 \\
3050-\text { Digestion }\end{array}$ \\
\hline $\mathrm{Zn}$ & FLAA & $\begin{array}{c}7951 \\
3050-D i g e s t i o n\end{array}$ \\
\hline
\end{tabular}

After digestion of all sludge samples, the digestates were analyzed for the heavy metals cadmium, chromium, nickel, lead, and zinc by the use of the Atomic Absorption Spectrophotometer (AAS) Buck Scientific Model 200. Severa! calibration standards were prepared either to establish the calibration curve or to use the concentration mode of the Buck Scientific 200.

The AAS results were compared with those in the DA's Standards of Maximum Allowable Level of Heavy Metals in Composts and Part 503 of the U.S. EPA. The values at all three sampling points were also evaluated against each other according to variations in concentrations for each week and at each sampling point. The results of the analyses done by the accredited laboratory were compared with those obtained by the research student.

\section{RESULTS AND DISCUSSION}

\section{Characterization of primary sludge, deinking sludge, and blended sludge}

The chemicals used in the recycling operations of the plant are not major sources of the chemicals lead, cadmium, and zinc. The chemicals sodium hydroxide, sodium silicate, hydrogen peroxide, and sodium hydrosulfite are common deinking chemicals. Although the company also utilizes a variety of surfactants, defoamers, and biocides, the heavy metals found after sludge analyses were neither major nor minor components of these chemicals.

Dyes are also used in papermaking. They serve as optical brighteners to achieve the required brightness of most white papers. The company employs a variety of dyes classified as Fluorescent Whitening Agents (FWA), such as Irgalite blue and Irgalite violet. The main types of FWAs used in the paper industry are derivatives of diaminostilbene disulphonic acid. They are applied mainly during the wet end, size press, and coating stages. Again, these are not point sources of the heavy metals found in the sludge after analyses wherein zinc and lead were the most prevalent metals. The chemicals used are possible sources of these metals if they exist in the chemical deinking compounds as impurities.

Another hypothesis is that these heavy metals results from the deinking and pretreatr.ient done on the recycling paper. The inks from the used paper are also possible sources of these contaminants. Likewise, because some inks still utilize lead compounds, zinc can find its way into the sludge since it serves as a filler in some paper.

The sludge samples were characterized as to heavy metal content and as to each metal's concentration at each sampling point. These values were evaluated and compared against each other to determine whether which metals are present in the sludge at higher amounts. The origin of the metals found in the sludge can be possibly due to the inks used or the impurities in the chemical additives used in papermaking.

\section{Comparison of metal concentrations per sampling point}

Figure 1 compares the concentrations of cadmium for each sampling day at each discharge point. The graph compares the average cadmium concentrations resulting from the AAS analysis of the sludge samples in the primary sludge, deinking sludge, and blended sludge.

The presence of cadmium in the samples was quite irregular. The primary sludge posted the 


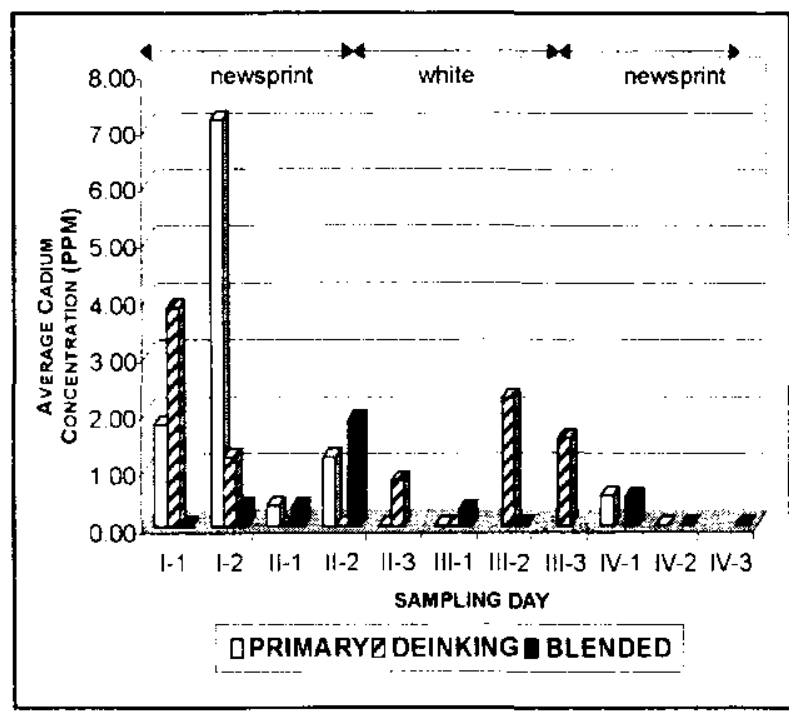

Figure 1. Average Cadmium Concentration in the Primary, Deinking, and Blended Sludge

highest cadmium concentration while the deinking sludge posted the most number of days that the metal was detected. Most of the time, cadmium was undetectable or was below detection limit. This could be attributed to the nonuse of cadmium compounds in most printing inks. Blended sludge posted the lowest reading compared to both primary sludge and blended sludge.

Figure 2 compares the average concentrations of lead for each sampling day at each discharge point. The graph shows the average concentrations of lead in the primary sludge, deinking sludge, and blended sludge. As can be seen from the graph, the deinking sludge posted a higher reading for each day compared to primary sludge and blended sludge. It also posted the highest concentration of lead for the whole sampling period. This result was expected because of the cleaning processes and of the chemicals added and removed during deinking. Although most of these contaminants ended up in the wastewater, still some found their way in the sludge.

Figure 3 compares the average concentration of zinc at the three discharge points. The figure shows the average concentrations of zinc in the primary sludge, deinking sludge, and blended sludge. The deinking sludge posted the highest concentration of zinc during the third week of sampling, while the lowest zinc concentration was noted during the first and second weeks of sampling.

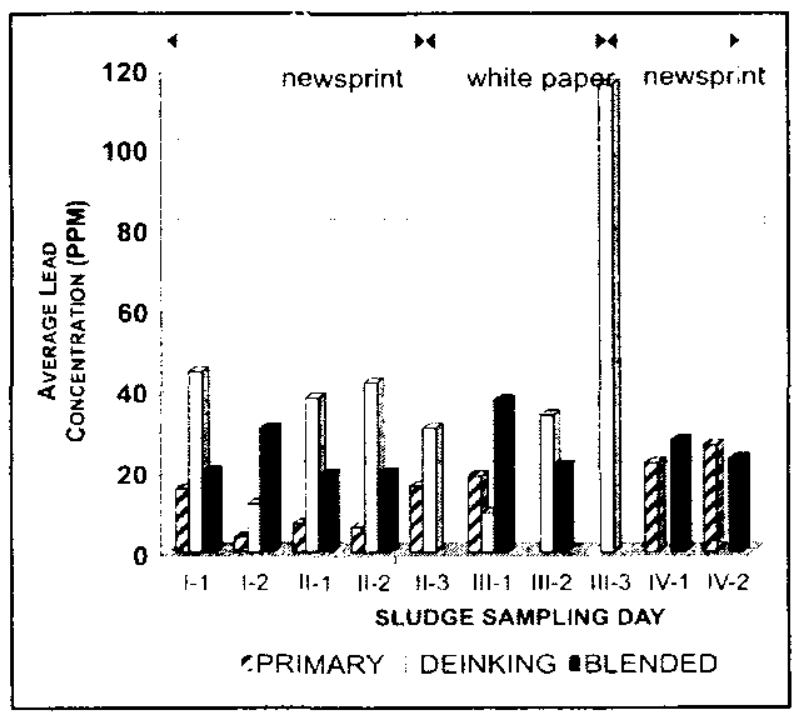

Figure 2. Average Lead Concentration in the Primary, Deinking, and Blended Sludge

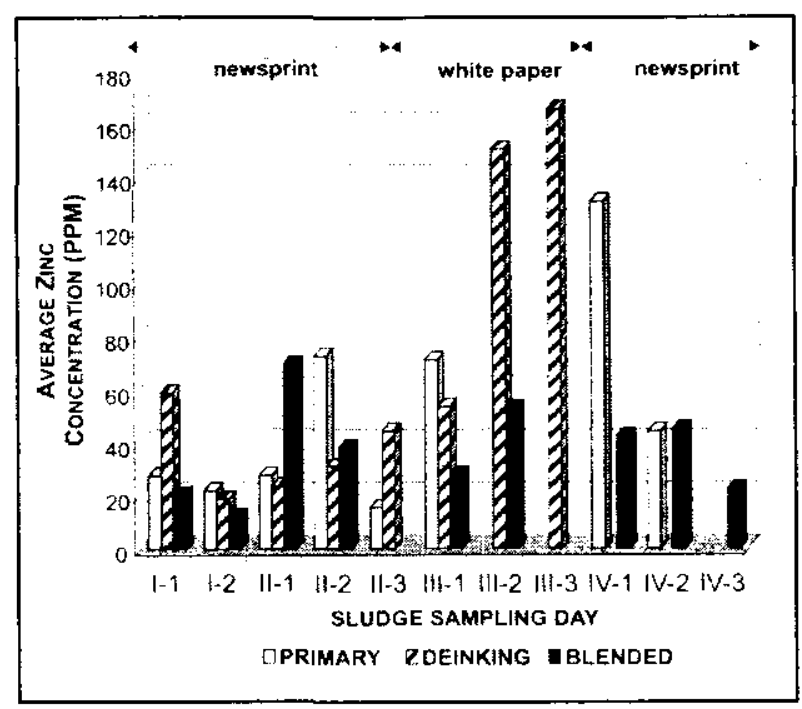

Figure 3. Average Zinc Concentration in the Primary, Deinking, and Blended Sludge

\section{Comparison of metal concentrations for each week}

Figure 4 shows the concentrations of cadmium at the sludge discharge points for the four weeks of sampling. Cadmium concentration was highest for primary sludge during the first week of sampling, for blended sludge during the second week, and for deinking sludge during the third week.

The fourth week of sampling posted the lowest cadmium concentration at all discharge points with the primary jludge having the maximum concentration within that week. 


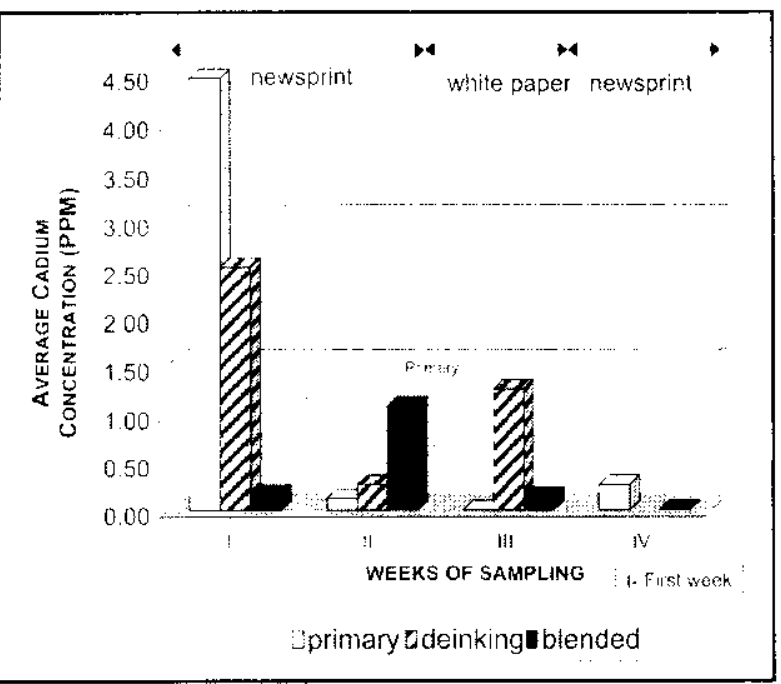

Figure 4. Average Cadmium Concentration in the Primary, Deinking and Blended Sludge for the Four Weeks of Sampling

Figure 5 shows the concentrations of the metal lead at the different discharge points for the four weeks of sampling. Lead has the highest concentration during the third week of sampling at the deinking sludge.

The lowest concentration of lead was posted during the first two weeks for primary sludge. In contrast, the third week of production posted the highest lead concentration for both deinking sludge and blended sludge. Note that the third week is the week for producing white paper.

Figure 6 shows the average zinc concentration for the four weeks of sampling at the different discharge points. The sampling posted the highest zinc concentration during the third week, followed by the fourth week of sampling. The first two weeks of sampling had the lowest zinc concentrations. Although the highest zinc concentration was for deinking sludge, blended sludge posted the highest reading during the second week of sampling.

\section{Evaluation of average results against regulatory standards}

Figure 7 compares the average concentrations of the metals cadmium, lead, and zinc in the primary sludge, deinking sludge and blended sludge against that specified in Part 503 of the United States' EPA. The graph shows that the AAS results at the three discharge points were very low compared to that outlined in the EPA sludge

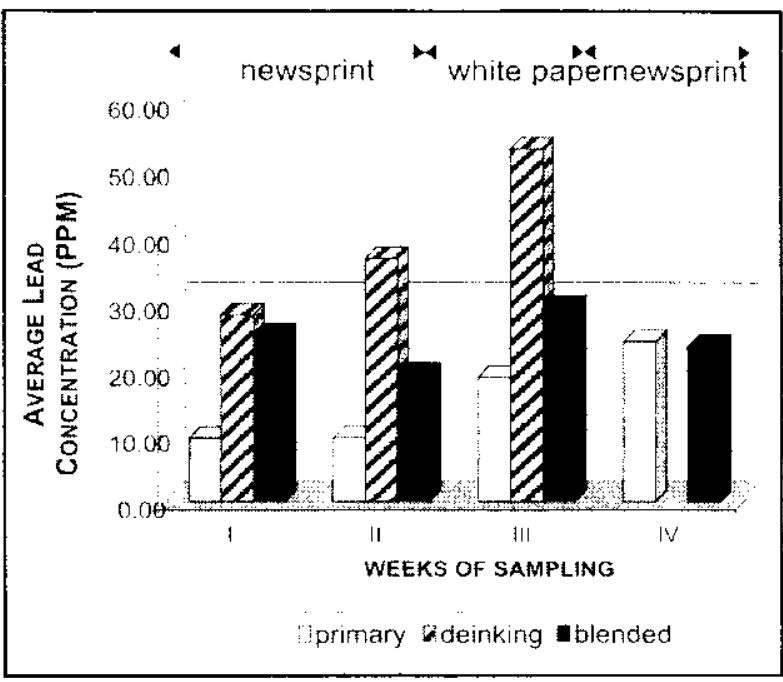

Figure 5. Average Lead Concentration in the Primary, Deinking, and Blended Sludge for the Four Weeks of Sampling

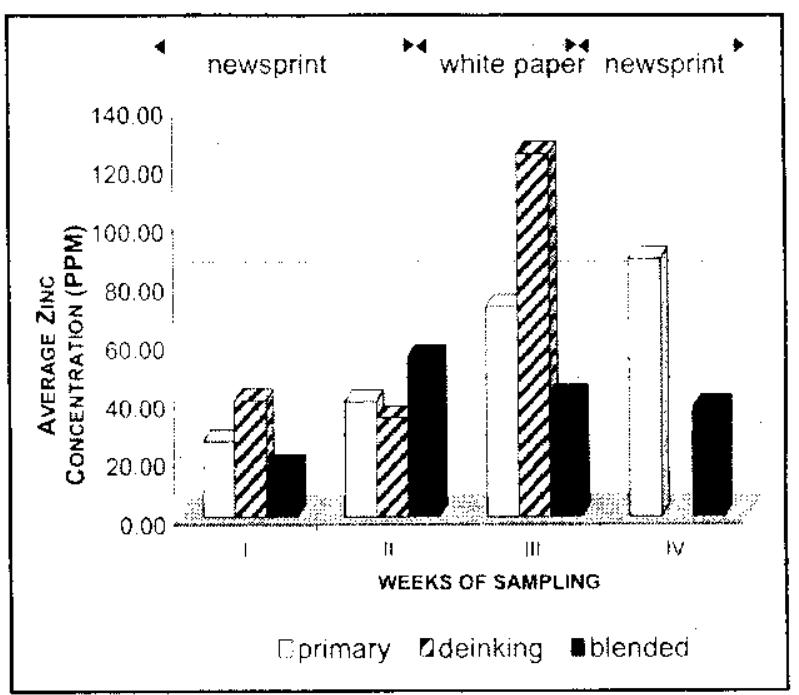

Figure 6. Average Zinc Concentration in the Primary, Deinking, and Blended Sludge for the Four weeks of Sampling

standards. Zinc had the highest concentration in the sludge results at $68.9 \mathrm{ppm}$ compared to the EPA sludge standard of $2,800 \mathrm{ppm}$.

Figure 8 , in contrast, compares the sludge results against the standards set by the the Philippine Department of Agriculture for organic fertilizers. Similarly, the sludge results were considerably lower than government standards. For instance, zinc posted the highest metal concentration during deinking at $68.90 \mathrm{ppm}$ against that of the DA's at $1,000 \mathrm{ppm}$, meanwhile, maximum lead concentration also during deinking was at 40.72 ppm against that of the DA's at $750 \mathrm{ppm}$. 


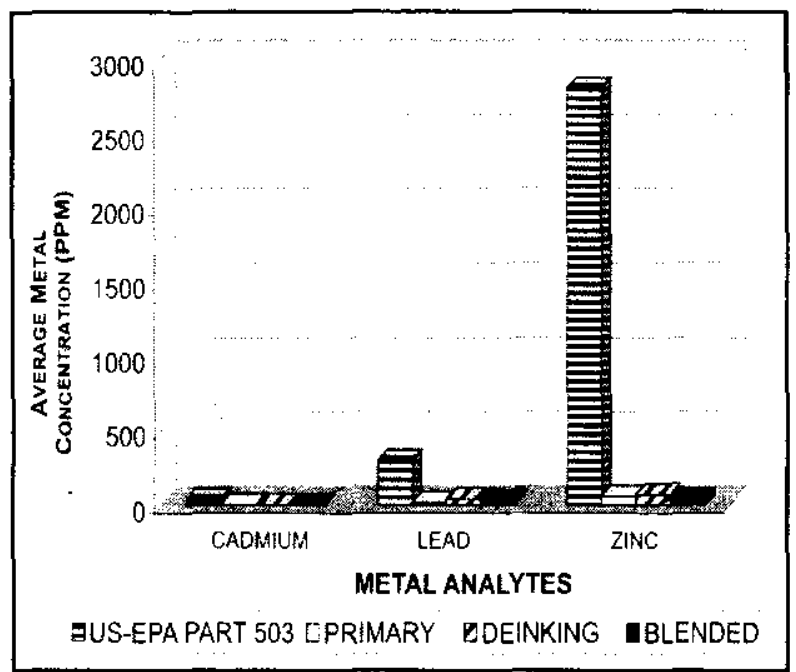

Figure 7. Sludge Results vs. U.S. EPA Part 503



Figure 9. Sludge Results us. Both U.S. EPA Part 503 and DA Standards

Figure 9 summarizes the average results for primary sludge, deinking sludge, and blended sludge against those of the DA standards for organic fertilizers and Part 503 of the U.S. EPA.

The results of the analysis clearly show very low heavy metals concentrations compared to the two benchmarks. Both local and international standards are very high compared to the sludge results so that even if there was $50-100 \%$ reduction in the weight of the sludge after composting, the results would still be very low. These results only point out the fact that the sludge at TIPCO does not contain hazardous levels of the heavy metals. Thus, the sludge can be landspread even without composting and still not exceed the levels set by both standards for the presence of heavy metals.

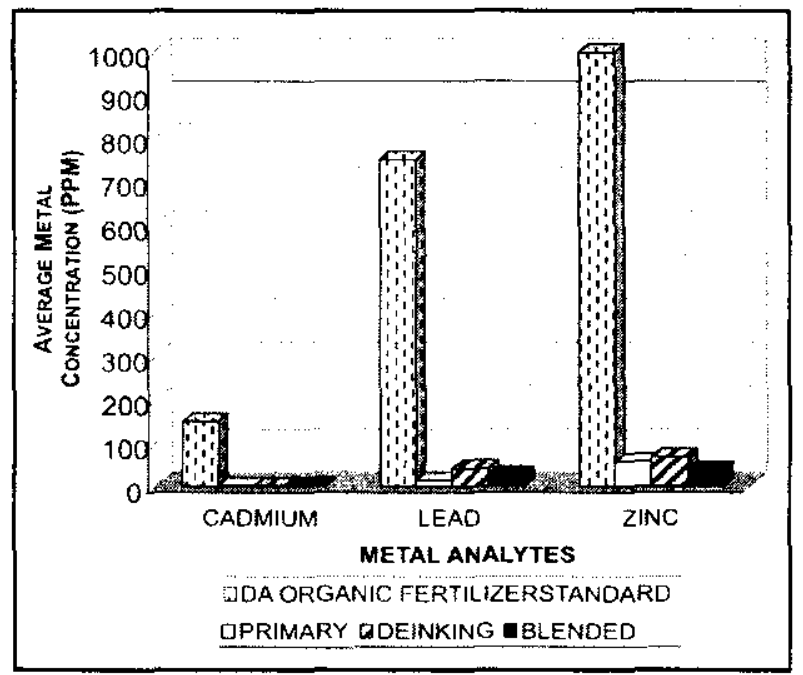

Figure 8. Sludge Results us. DA Standards

\section{CONCLUSIONS}

The results of the AAS analysis revealed that (a) the metals cadmium, lead, and zinc were detected at all three sampling points, while (b) the metals chromium, nickel, and mercury were consistently nondetectable in all the samples.

Although the deinking sludge revealed higher concentrations of lead and zinc, cadmium was slightly higher in primary sludge than in the deinking sludge. The blended sludge, which was the sludge for final disposal, showed lower concentrations of zinc and cadmium. Lead, however, was slightly higher in the primary sludge.

Lead and zinc posted the highest concentrations during the white run production, while cadmium was highest during the first week of the run. Note that the production of white paper, which makes use of old magazines and coated book papers, required a more thorough removal of inks and fillers particularly from magazines. Hence, the major source of paper sludge contamination are the dyes added to the paper by manufacturers and the inks added by printers.

The results of the study showed higher lead and zinc content at the deinking treatment. Most of the heavy metals detected could be traced from this sludge as a result of deinking newspapers and magazines. Thus, it was recommended that the sludge from the deinking treatment be segregated from the rest of the sludge before composting of the blended sludge. 
After achieving positive results from the analysis and comparison of the metal concentrations with those specified in the regulatory standards, composting the sludge for final disposal is the next step towards proving that composting is indeed an effective alternative to the traditional means of sludge management.

\section{ACKNOWLEDGMENTS}

The authors would like to extend their sincerest thanks to: the Swedish International Development Cooperation Agency (SIDA), the funding agency of the ARRPET through the Asian Institute of Technology (AIT), Thailand; Trust International Paper Corporation (TIPCO), through Engr. Roland Peña of the Environmental Management Department; and Engr. Jurex Gallo, graduate of the Master of Engineering Program of DLSU-Manila and member of the ARRPET Minor Issue Group.

\section{REFERENCES}

Bajpai, P., Bajpai, P. K., and Kondo, R. (1999). "Management of wastewater treatment sludges," Biotechnology for environmental protection in the pulp and paper industry, Springer-Verlag, Berlin/ Heidelberg, Germany.

Bantayan, R., and Razal, R. A. (2001, October). "Status of environmental protection and control in philippine pulp and paper mills," Inpaper International.

Barry, G. A., Gardner, E. A., Rayment, G. E., and Bloesch, P. M. (1998). Recycling organic materials on agricultural lands, Department of Natural Resources and CRC for Sustainable Sugar Production.

Conservatree. "Environmentally sound paper overview: Essential issues," Part III-Making Paper: Content. Online: http://www conservatree.Com/learn/ Essentiallssues/EIPaperContents/ shtml. Accessed: 12 January 2003.

Gallo, J., and Gallardo, S. M. (2002, October). "Assessment of pulp and paper industry discharges in the Philippines." Chemical Engineering Congress, Manila.
MacGuire, F. (1997, November). Paper recycling-Exposing the myths. Briefing Paper, Friends of the Earth Ltd., London, England.

McKinney, R. W. J. (1995, January). Technology of paper recycling, Blackie Academic \& Professional, London, England.

Medvitz, A. (1998, January 21-22). "Sludge, sludge on the range: Unresolved science in the 503 Regulations." The 1998 California Plant and Soil Conference: Agricultural Challenges in an Urbanizing State, California Chapter of American Society of Agronomy and California Fertilizer Association.

Obcemea, W. N. (2001, August 31). "Technical requirements and potential markets of compost." National Solid Waste Commission, Seminar on Ecological Solid Waste Management, Pasig City.

Rios, A. T. (2001, May 23-25). "Overview of the paper industry." Pulp and Paper Manufacturers Association, $5^{\text {th }}$ International Workshop on the Use of Paper Industry Sludges in Environmental Geo-Technology and Construction, Makati City.

U.P. Business Research Foundation, Inc. (1990, February). "Study on waste paper recovery," Executive Summary.

U.S. Environmental Protection Agency. (1994) SW-846: Test methods for evaluating solid wastes, Physical/chemical methods, vol. 2, $3^{\text {rd }}$ ed., Washington, D.C. Online: http://www.greatescapesmotors.com/ members/sosan/Sops/SW846SOPS. html. Accessed: 20 February 2002.

U.S. Environmental Protection Agency Part 503. Online: http://www. users, erols.com/ taylew/503.html. Also: http:// www.epa.gov/docs/epacfr40/chapt-I.info/

Webb, L.(1996, November). "A host of options available for sludge," Pulp and Paper International, 44-8.

Wiseman, N., Rook, M. J., Guillet, F., and Muratore, E. (1999, March). "The composition of deinking sludges arising from paper recycling, and implications for filler recovery," Das Papier, T36-T39. 